\title{
Produção de morangos a partir de fertilizantes alternativos em pré-plantio
}

\author{
Pre-planting fertilization effects on strawberry fruit yield
}

\section{Gerson Kleinick Vignolo ${ }^{I}$ Vanessa Fernandes Araújo ${ }^{\mathrm{I}}$ Roberta Jeske Kunde Carlos Augusto Posser Silveira ${ }^{\mathrm{II}}$ Luis Eduardo Corrêa Antunes ${ }^{\mathrm{I}^{*}}$}

RESUMO

\begin{abstract}
O trabalho teve como objetivo avaliar doses de fertilizantes alternativos na adubação de pré-plantio quanto à produção de frutos de morangueiro. Os tratamentos foram baseados em doses de adubação NPK $\left(\mathrm{kg} \mathrm{ha}^{-1}\right)$ recomendada para a cultura do morangueiro em que as doses de torta de mamona (TM), fosforita alvorada (FA) e cloreto de potássio (KCl) variaram de acordo com a recomendação da análise de solo. Os tratamentos foram dispostos em delineamento em blocos casualizados em parcelas subdivididas, sendo as cultivares dispostas na parcela e as adubações na subparcela. Foi utilizado um esquema fatorial $2 x 4$, em que o fator cultivar apresentou dois níveis: 'Camarosa' e 'Camino Real', e o fator adubação de pré-plantio, quatro níveis. As avaliações realizadas foram produção de frutos por planta, massa seca da parte aérea e índice de clorofila. A cultivar 'Camarosa' apresentou maior número e massa de frutos por planta e maior massa seca da parte aérea. A cultivar 'Camino Real' apresentou maior massa média por fruto e maior índice de clorofila. Com relação às doses de adubação de pré-plantio que propiciaram maior número e massa de frutos por planta, foram $1.937 \mathrm{~kg} \mathrm{ha}^{-1} e$ $1.713 \mathrm{~kg} \mathrm{ha}^{-1}$ de adubo, respectivamente.
\end{abstract}

Palavras-chave: Fragaria $x$ ananassa, nutrição mineral, adubação alternativa.

\section{ABSTRACT}

The study aimed to evaluate the doses of alternative fertilizer pre-planting fertilization on strawberries yield. The treatments were based on doses of NPK $\left(\mathrm{kg} \mathrm{ha}^{-1}\right)$ recommended for strawberry culture in which the doses of castor bean (TM), phosphorite dawn (FA) and potassium chloride ( $\mathrm{KCl})$ varied according to the recommendation of the soil analysis. The treatments were arranged in randomized blocks design at split plots with cultivars in the plot and fertilization in the sub-plot. It was used a factorial $2 \times 4$ arrangement, in which the cultivar factor had two levels: 'Camarosa' and 'Camino Real', and the pre-planting fertilizer factor with four levels. The evaluations were fruit yield per plant, shoot dry mass and chlorophyll content. 'Camarosa' cultivar showed a greater number and weight of fruits per plant and higher dry mass shoots. Cultivar 'Camino Real' had the largest average per fruit and increased chlorophyll content. Regarding the fertilization rates of preplanting, which fostered a greater number and weight of fruits per plant, it was $1937 \mathrm{~kg} \mathrm{ha}^{-1}$ and $1713 \mathrm{~kg} \mathrm{ha}^{-1}$ of fertilizer, respectively.

Key words: Fragaria $x$ ananassa, mineral nutrition, alternative fertilization.

\section{INTRODUÇÃO}

A produção de morangos (Fragaria $\mathrm{x}$ ananassa Duch.) no Brasil tem crescido nos últimos anos, estimando-se uma produção anual de 100 mil toneladas em 3.500ha (ANTUNES et al., 2010; COSTA et al., 2011). O Brasil ainda não aparece nas estatísticas entre os grandes produtores mundiais, mas começa a se destacar, devido às condições naturais favoráveis ao cultivo e a produção em quase todos os meses do ano(ANTUNES \& REISSER JÚNIOR, 2007).

As cultivares 'Camarosa' e 'Camino Real' estão entre as principais cultivares utilizadas no Brasil, ambas lançadas nos Estados Unidos (OLIVEIRA et al., 2007). Cada cultivar de morangueiro difere pela

IPrograma de Pós-graduação em Agronomia, Universidade Federal de Pelotas (UFPel), Pelotas, RS, Brasil.

"Embrapa Clima Temperado, BR 392, Km 78, 96001-970, Pelotas, RS, Brasil. E-mail: luis.eduardo@cpact.embrapa.br. *Autor para correspondência. 
adaptação regional, fazendo com que uma cultivar se desenvolva satisfatoriamente em uma região e não apresente o mesmo desempenho produtivo em outro local (UENO, 2004).

A adubação do morangueiro é uma das principais práticas responsáveis pelo aumento da produtividade, qualidade e conservação pós-colheita. Entretanto, poucos são os trabalhos de pesquisa sobre a nutrição da cultura no Brasil (PREZOTTI, 2006). Segundo FILGUEIRA (2003), aplicações de nitrogênio e de fósforo elevam, significativamente, a produtividade do morangueiro, inclusive em solos considerados férteis, já o potássio é o macronutriente que mais favorece o aprimoramento na qualidade do morango.

Dentre as fontes orgânicas, a torta de mamona é uma matéria-prima importante para o fornecimento de nutrientes, sendo um co-produto da produção de biodisel, a qual possui excelentes propriedades químicas para uso na agricultura e tem elevado teor de nitrogênio, sendo seu principal uso como adubo orgânico para as culturas (COSTA et al., 2007). O fosfato natural (FN) é utilizado há décadas como fertilizante em diferentes culturas, sendo variável o nível de sucesso (SOUZA, 1996). Os solos brasileiros são carentes de fósforo $(\mathrm{P})$, em consequência do material de origem e da forte interação do P com o solo, uma vez que menos de $0,1 \%$ deste elemento encontrase em solução (CORRÊA, 2004).

Ao se observar a produção agrícola, podese perceber que a agricultura "moderna" permite o uso dos solos de forma intensiva, baseada em pacotes tecnológicos de elevada produtividade. Entretanto, esse padrão de produção não se ajustou à agricultura de forma generalizada, aumentando a diferença entre agricultores fortes e aqueles que não conseguiram elevar suas receitas ou produtividades (MAZOYER \& ROUDART, 2007). Existe a necessidade de uma adubação mais equilibrada e sustentável ao longo do tempo, evitando assim o processo de salinização do solo, comum em plantios intensivos de grãos (MIRANDA et al., 2008; SILVA et al., 2011) e hortaliças.

Nesse sentido, objetivou-se, neste trabalho, avaliar doses de fertilizantes alternativos em pré-plantio quanto à eficiência agronômica na produção de morangueiro.

\section{MATERIAL E MÉTODOS}

O experimento foi implantado em maio de 2009 em uma propriedade particular localizada na Estrada da Gama, 9o Distrito de Pelotas-RS (Latitude $31^{\circ} 45^{\prime}$; Longitude 52 $21^{\prime}$; Altitude de 17 metros). O solo do local onde foi instalado o experimento foi classificado como Argissolo vermelho-amarelo. A recomendação de adubação em pré-plantio foi baseada nos resultados da análise do solo da área experimental (Tabela 1).

Os tratamentos foram baseados em doses de adubação NPK $\left(\mathrm{kg} \mathrm{ha}^{-1}\right)$ recomendadas para a cultura do morangueiro (CQFS, 2004), sendo que a adubação com a dose recomendada apresentou $120 \mathrm{~kg} \mathrm{ha}^{-1} \mathrm{de} \mathrm{N}$, $90 \mathrm{~kg} \mathrm{ha}^{-1} \mathrm{de}_{2} \mathrm{P}_{2} \mathrm{O}_{5}$ e $60 \mathrm{~kg} \mathrm{ha}^{-1}$ de $\mathrm{K}_{2} \mathrm{O}$. As fontes de NPK foram, respectivamente, Torta de Mamona (TM- 5,0\% de N), Fosforita Alvorada (FA- 24\% $\mathrm{P}_{2} \mathrm{O}_{5}$ ) e Cloreto de Potássio $\left(\mathrm{KCl}-60 \%\right.$ de $\left.\mathrm{K}_{2} \mathrm{O}\right)$. Os tratamentos foram dispostos em delineamento em blocos casualizados em parcelas subdivididas, sendo as cultivares dispostas na parcela e as adubações na subparcela. Foi utilizado

Tabela 1- Análise de solo antes da instalação do experimento e após tratamentos de adubação em pré-plantio. Embrapa Clima Temperado, UFPel/FAEM. Pelotas/RS, 2011.

\begin{tabular}{|c|c|c|c|c|}
\hline pH (água) & Índice SMP & M.O. & K & $\mathrm{P}$ \\
\hline \multirow{3}{*}{5,1} & \multirow{3}{*}{5,7} & $\%$ & \multicolumn{2}{|c|}{ - } \\
\hline & & 2,0 & 255,0 & 204,4 \\
\hline & & Baixo & Muito Alto & Muito Alto \\
\hline Adubação & $P$ & $\mathrm{~K}$ & $\mathrm{Ca}$ & $\mathrm{Mg}$ \\
\hline$\left(\mathrm{kg} \mathrm{ha}^{-1}\right)$ & & & & \\
\hline 0 & $237,4^{\text {ns }}$ & $243,2^{\text {ns }}$ & $4,2^{\mathrm{ns}}$ & $2,2^{\mathrm{ns}}$ \\
\hline 958 & 230,8 & 231,0 & 4,2 & 2,2 \\
\hline 1916 & 209,5 & 239,3 & 4,1 & 2,5 \\
\hline 2874 & 242,4 & 233,5 & 4,3 & 2,2 \\
\hline $\mathrm{CV}(\%)$ & 15,0 & 19,5 & 5,7 & 8,5 \\
\hline $\begin{array}{l}\text { Adubação } \\
\left(\mathrm{kg} \mathrm{ha}^{-1}\right)\end{array}$ & $\mathrm{Cu}$ & $\mathrm{Fe}$ & $\mathrm{Zn}$ & $\mathrm{Mn}$ \\
\hline 0 & $2,3^{\mathrm{ns}}$ & $111,3^{\text {ns }}$ & $5,6^{\text {ns }}$ & $114,5^{\mathrm{ns}}$ \\
\hline 958 & 2,3 & 105,8 & 6,9 & 113,1 \\
\hline 1916 & 2,1 & 97,2 & 7,0 & 108,8 \\
\hline 2874 & 2,7 & 111,7 & 6,1 & 114,6 \\
\hline $\mathrm{CV}(\%)$ & 16,8 & 16,6 & 38,1 & 18,3 \\
\hline
\end{tabular}

Ciência Rural, v.41, n.10, out, 2011. 
um esquema fatorial $2 \times 4$, em que o fator cultivar apresentou dois níveis: 'Camarosa' e 'Camino Real', e o fator adubação de pré-plantio, quatro níveis. Os níveis de adubação em pré-plantio foram $0 \mathrm{~kg} \mathrm{ha}^{-1}$ de adubo (0kg ha-1 de TM, FA e $\mathrm{KCl}) ; 958 \mathrm{~kg} \mathrm{ha}^{-1}$ de adubo (800kg ha $^{-1}$ de TM, $125 \mathrm{~kg} \mathrm{ha}^{-1}$ de FAe $33 \mathrm{~kg} \mathrm{ha}^{-1}$ de $\mathrm{KCl}=1 / 3 \mathrm{da}$ dose recomendada); $1916 \mathrm{~kg} \mathrm{ha}^{-1}$ de adubo (1600 $\mathrm{kg} \mathrm{ha}^{-1}$ de TM, 250kg ha-1 de FA e $67 \mathrm{~kg} \mathrm{ha}^{-1}$ de $\mathrm{KCl}=2 / 3$ da dose recomendada); $2874 \mathrm{~kg} \mathrm{ha}^{-1}$ de adubo (2400 $\mathrm{kg} \mathrm{ha}^{-1}$ de TM, 375 kg ha ${ }^{-1}$ de FA e $100 \mathrm{~kg} \mathrm{ha}^{-1}$ de $\mathrm{KCl}=$ dose recomendada). Foram realizadas apenas essas adubações descritas, não sendo realizada adubação em cobertura. Cada parcela foi constituída de 12 plantas com espaçamento de $0,30 \mathrm{~m}$ x $0,30 \mathrm{~m}$ e quatro repetições. Foram utilizados filme de polietileno preto, túnel baixo de polietileno transparente e irrigação por gotejamento.

Foram realizadas avaliações de número e massa de frutos por planta; massa por fruto; massa seca da parte aérea ao final do experimento. O material retirado de cada unidade experimental foi acondicionado em sacos de papel, seco a $65^{\circ} \mathrm{C}$ até atingir massa constante, sendo considerada a soma da massa das folhas, pecíolos e coroa; teor de clorofila, medido através de clorofilomêtro Soil Plant Analysis Development (SPAD-502, Minolta, Japão), em outubro de 2009, medindo duas folhas planta ${ }^{-1}$. Também foram medidos os teores foliares de macro e micronutrientes, sendo realizada coleta em setembro de duas folhas por planta e coleta de solo ao final do experimento, contendo três subamostras por parcela. As colheitas começaram em 3 de setembro de 2009 e foram realizadas duas vezes por semana, colhendo-se frutos na fase de maturação com $75 \%$ da epiderme vermelha ou mais.

Os dados obtidos referentes às cultivares foram submetidos à análise de variância e a comparação de médias efetuada pelo teste Tukey em nível de 5\% de probabilidade. Foram apresentadas as regressões do fator quantitativo doses de adubação em pré-plantio apenas quando houve diferença significativa. $\mathrm{O}$ programa estatístico utilizado foi o Winstat, versão 2.0 (MACHADO \& CONCEIÇÃO, 2003).

\section{RESULTADOS E DISCUSSÃO}

Independentemente da dose de adubação aplicada em pré-plantio, a cultivar 'Camarosa' proporcionou maior número de frutos $(43,6$ frutos planta $\left.^{-1}\right)$ e de massa de frutos por planta $\left(813,2 \mathrm{~g} \mathrm{planta}^{-1}\right)$ (Tabela 2). A menor produtividade de 'Camino Real' pode ser atribuída às características genéticas, que, de acordo com SHAW (2004), é reconhecidamente menos produtiva que 'Camarosa'. OLIVEIRA et al. (2008), avaliando o desempenho agronômico de três cultivares de morangueiro no município de Pelotas-RS, obtiveram 55 e 44 frutos por planta para as cultivares 'Camarosa' e 'Camino Real', respectivamente. A produção observada por este mesmo autor foi de $1.121 \mathrm{~g} \mathrm{planta}^{-1}$ utilizando 'Camino Real' e $1.038 \mathrm{~g}$ planta $^{-1}$ com 'Camarosa', valores superiores aos encontrados no presente estudo. Já MARTINS (2010), testando sete cultivares de morangueiro em sistema orgânico, verificaram produção de $1.004 \mathrm{~g}$ planta $^{-1}$ na cultivar 'Camarosa' e 604g planta-1 em 'Camino Real'.

ANTUNES et al. (2010), avaliando a produção e qualidade de seis cultivares de morangueiro na região de Pelotas-RS, observaram produção de frutos por planta semelhante ao verificado no presente estudo, já que a cultivar 'Camarosa' apresentou 877,51 g planta-1. A maior produção apresentada pela cultivar 'Camarosa' está relacionada ao maior número de frutos por planta produzidos em relação à cultivar 'Camino Real' .

A massa média por fruto ao longo do período de produção foi significativamente maior para 'Camino Real' (20,2 g fruto $\left.^{-1}\right)$ em relação à cultivar 'Camarosa' (Tabela 2). A maior quantidade de frutos produzidos pela cultivar 'Camarosa' resultou em menor massa média por fruto. Ainda assim, o valor médio de $18,5 \mathrm{~g}$ por fruto apresentado pela cultivar 'Camarosa' é considerado de boa qualidade comercial. MARTINS (2010), corroborando os resultados do presente trabalho, encontrou maior massa média por fruto na cultivar 'Camino Real' do que em 'Camarosa'. CHANDLER et al. (2005), ao testar diferentes cultivares na Flórida,

Tabela 2 - Número (NF), massa de frutos por planta (MF), massa média por fruto (MMF), massa seca da parte aérea (MSPA) e índice de clorofila das folhas (IC) em função de diferentes adubações de pré-plantio e cultivares de morangueiro, safra 2009. Embrapa Clima Temperado, UFPel/FAEM. Pelotas/RS, 2011.

\begin{tabular}{|c|c|c|c|c|c|}
\hline Cultivar & $\mathrm{NF}$ (frutos planta ${ }^{-1}$ ) & MF (g planta $\left.{ }^{-1}\right)$ & $\operatorname{MMF}\left(\mathrm{g}\right.$ fruto $\left.^{-1}\right)$ & $\operatorname{MSPA}\left(\mathrm{g} \mathrm{planta}^{-1}\right)$ & IC (índice SPAD) \\
\hline 'Camarosa' & 43,6 a & $813,2 \mathrm{a}$ & $18,5 \mathrm{~b}$ & $66,1 \mathrm{a}$ & $44,3 \mathrm{~b}$ \\
\hline 'Camino Real' & $26,5 \mathrm{~b}$ & $540,4 \mathrm{~b}$ & $20,2 \mathrm{a}$ & $49,6 \mathrm{~b}$ & 47,6 a \\
\hline CV (\%) & 9,6 & 14,1 & 7,1 & 28,4 & 2,8 \\
\hline
\end{tabular}

Médias seguidas de mesma letra, nas colunas, não diferem significativamente entre si, pelo teste de Tukey (5\%).

Ciência Rural, v.41, n.10, out, 2011. 
verificaram a superioridade de 'Camino Real' em relação ao tamanho de frutos, destacando a baixa quantidade de frutos pequenos (menos de $1 \%$ com massa inferior a $10 \mathrm{~g}$ ).

As doses de adubação de pré-plantio influenciaram significativamente no número e na massa de frutos por planta, seguindo um modelo de resposta quadrático (Figura 1). Esse comportamento sugere que as dosagens de adubação de pré-plantio estabelecidas nos tratamentos foram adequadas para o estudo, induzindo aumentos significativos na produção com as dosagens iniciais, atingindo um ponto de máxima de $1.937 \mathrm{~kg} \mathrm{ha}^{-1} \mathrm{e} 1.713 \mathrm{~kg} \mathrm{ha}^{-1}$ para as variáveis número e massa de frutos por planta, respectivamente, e decrescendo nas maiores dosagens (Figura 1). Essa adubação de $1.713 \mathrm{~kg} \mathrm{ha}^{-1}$ corresponde à mistura de $1392 \mathrm{~kg} \mathrm{ha}^{-1}$ de torta de mamona, $256 \mathrm{~kg} \mathrm{ha}^{-1}$ de fosforita alvorada e $65 \mathrm{~kg} \mathrm{ha}^{-1}$ de cloreto de potássio.

O uso de torta de mamona na adubação do morangueiro possivelmente tenha auxiliado no incremento da produção de frutos, principalmente devido ao baixo teor de matéria orgânica no solo (Tabela 1). KIRSCHBAUM et al. (2006), testando doses de $\mathrm{N}$ em cultivares de morangueiro, constataram que houve perda de produção quando utilizaram doses acima de $155 \mathrm{~kg} \mathrm{~N} \mathrm{ha}^{-1}$. HOCHMUTH et al. (2006) avaliaram doses de $\mathrm{N}$ entre $0,28 \mathrm{e} 1,40 \mathrm{~kg} \mathrm{ha}^{-1}$ por dia (50 a $250 \mathrm{~kg} \mathrm{ha}^{-1}$ por ciclo) e verificaram que a produção total de frutos aumentou quando as doses de $\mathrm{N}$ aumentaram até $0,54 \mathrm{~kg} \mathrm{ha}^{-1}$ por dia, ou seja, $96 \mathrm{~kg} \mathrm{ha}^{-1}$.

O potássio $(\mathrm{K})$ foi responsável pela diminuição da produção de frutos quando se utilizou doses acima de $1.917 \mathrm{~kg} \mathrm{ha}^{-1}$ de adubo, tendo sido fitotóxico para as plantas, pois já havia um teor elevado desse nutriente no solo (Figura 2). ANDRIOLO et al. (2010), testando diferentes doses de potássio em morangueiro, observaram que a dose mais elevada utilizada no experimento prejudicou a produção e o número de frutos em relação às menores doses. De acordo com o autor, a causa dessa redução na produção de frutos seria o efeito combinado da baixa

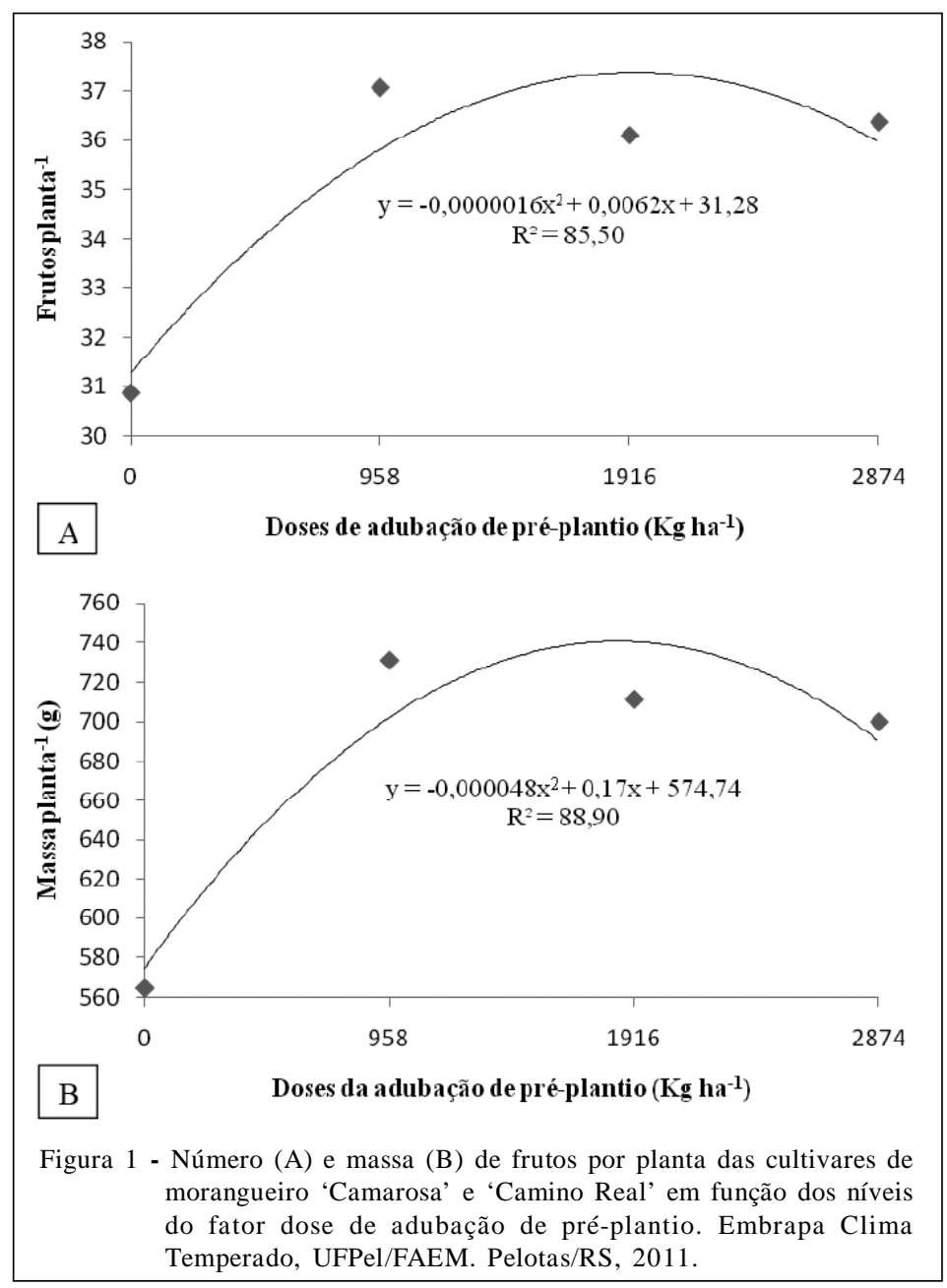

Ciência Rural, v.41, n.10, out, 2011. 


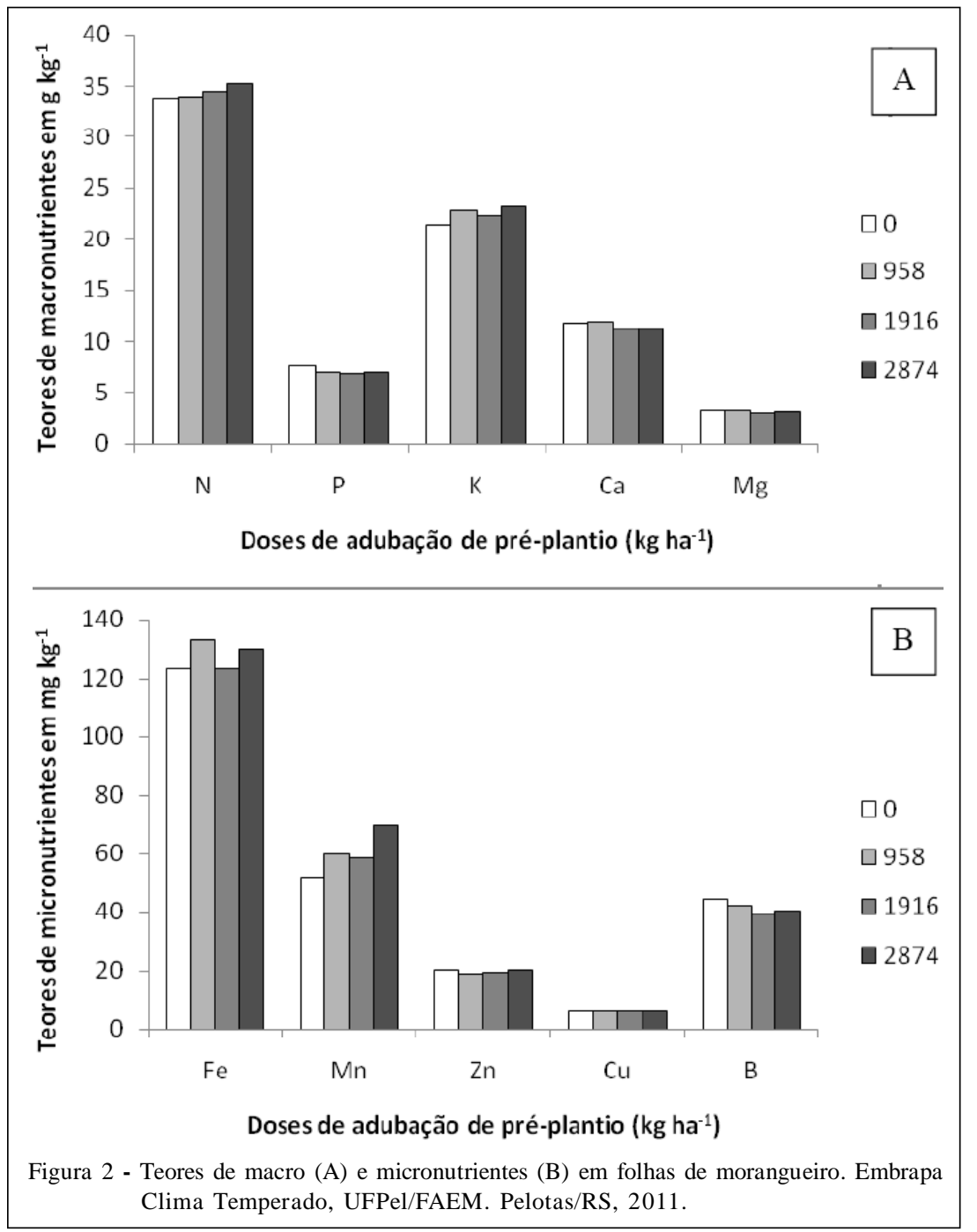

disponibilidade de assimilados, decorrente da redução no crescimento da área foliar e de perturbações na absorção de cálcio e/ou magnésio induzidas pelo potássio.

Com relação à massa seca da parte aérea (MSPA), a cultivar 'Camarosa' apresentou produção de MSPA de 66,1g planta $^{-1}$, valor superior aos 49,6g planta $^{-1}$ apresentado pela cv. 'Camino Real' (Tabela 2). Em termos percentuais, a produção de MSPA da 'Camarosa' foi 24\% maior que da 'Camino Real', indicando que a cv. 'Camarosa' é mais vigorosa. Esses resultados estão de acordo com SHAW (2004), o qual relata que a cultivar 'Camino Real' é pouco vigorosa, mais compacta, ereta e aberta do que 'Camarosa'.

STRASSBURGER (2010), avaliando o crescimento de cultivares de morangueiro, observaram resultados semelhantes ao presente trabalho, já que a cultivar 'Camarosa' apresentou 89,8g planta $^{-1}$, sendo superior à 'Camino Real' com 47,1g planta ${ }^{-1}$. O autor relata que a maior produção de massa seca da 'Camarosa' pode ser associada à maior capacidade de expansão do aparato fotossintético, ocorrendo uma maior interceptação da radiação solar e maior produção de fotoassimilados. FERNANDEZ et al. (2001), avaliando o crescimento e desenvolvimento de três cultivares de morangueiro, constataram que a cultivar 'Camarosa' possui $54 \mathrm{~g}_{\text { }}$ lanta $^{-1}$ de matéria seca da parte aérea (folhas e coroa), sendo superior às cultivares Chandler e Sweet Charlie.

$\mathrm{Na}$ avaliação do índice de clorofila, o efeito do fator cultivar foi significativo, tendo 'Camino Real' apresentado maior índice de clorofila em relação à cv. 'Camarosa'. Já para o fator doses de adubação em préplantio, não houve significância, assim como para a interação entre eles. A cultivar 'Camino Real' apresentou índice SPAD de 47,7, valor superior aos 
44,5 encontrados em 'Camarosa' (Tabela 2). Apesar de 'Camino Real' ter apresentado maior índice SPAD, isso não influenciou na produtividade, pois a quantidade de massa seca da parte aérea de 'Camarosa' foi superior, tendo assim maior número de folhas para realizar fotossíntese. MACIT et al. (2007) verificaram índice SPAD de apenas 30,25 em folhas de 'Camarosa', valor inferior ao encontrado no presente estudo. SANTOS (2010), após resultados de pesquisas realizadas em morangueiro, nas quais analisou o efeito de diferentes fontes de $\mathrm{Ne} \mathrm{S}$, não verificou diferenças significativas nos teores de clorofila das plantas sob diferentes adubações, encontrando média de 44,75 de índice SPAD.

\section{CONCLUSÃO}

A cultivar 'Camarosa' apresenta maior produção de frutos do que 'Camino Real'. As doses de adubação em pré-plantio que propiciam maior massa de frutos por planta são $1392 \mathrm{~kg} \mathrm{ha}^{-1}$ de torta de mamona, $256 \mathrm{~kg} \mathrm{ha}^{-1}$ de fosforita alvorada e $65 \mathrm{~kg} \mathrm{ha}^{-1}$ de cloreto de potássio.

\section{REFERÊNCIAS}

ANDRIOLO, J.L. et al. Doses de potássio e cálcio no crescimento da planta, na produção e na qualidade de frutas do morangueiro em cultivo sem solo. Ciência Rural, Santa Maria, v.40, n.2, p.267-272, 2010. Disponível em: <http://www.scielo.br/ s c i e lo.ph p s c ri p t = s c i $84782010000200003 \& \operatorname{lng}=\mathrm{pt} \& \mathrm{nrm}=\mathrm{iso} \& \operatorname{lng}=\mathrm{pt}>$. Acesso em: 01 fev. 2011.

ANTUNES, L.E.C.; REISSER JÚNIOR, C. Produção de morangos. Jornal da Fruta, Lages, v.15, n.191, p.22-24, 2007.

ANTUNES, L.E.C. et al. Yield and quality of strawberry cultivars. Horticultura Brasileira, Brasília, v.28, n.2, p.222226, 2010.

CHANDLER, C.K. et al. Evaluation of strawberry cultivars grown under a high plastic tunnel in west central Florida. Proceedings of the Florida State Horticultural Society, Winter Haven, v.118, p.113-114, 2005.

CORRÊA, J.C. et al. Fósforo no solo e desenvolvimento de soja influenciados pela adubação fosfatada e cobertura vegetal. Pesquisa Agropecuária Brasileira, Brasília, v.39, n.12, p.1231-1237, 2004. Disponível em: <http://www.scielo.br/ s c i e lo.ph p s c ri p t $=\mathrm{sc} \mathrm{i}_{-}$pd f \& p id = S $0100-$ 204X2004001200010\&lng=pt\&nrm=iso\&tlng=pt $>$. Acesso em: 01 fev. 2011.

COSTA, F.X. et al. Resposta ao efeito da compactação do solo adubado com torta de mamona nos macronutrientes das folhas da mamoeira. In: CONGRESSO DA REDE BRASILEIRA DE TECNOLOGIA DE BIODISEL, 2., 2007, Brasilia-DF. Anais... Brasilia-DF: MCT/ABIPTI, 2007. CD-ROM.
COSTA, R.C. da et al. Telas de sombreamento na produção de morangueiro em ambiente protegido. Horticultura Brasileira, Brasília, v.29, n.1, p.98-102, 2011.

COMISSÃO DE QUíMICA E FERTILIDADE DO SOLO. Manual de adubação e de calagem para os estados do RS e SC. 10.ed. Porto Alegre: Sociedade Brasileira de Ciência do Solo- Núcleo Regional Sul, 2004. 394p.

FERNANDEZ, G.E. et al. Strawberry growth and development in an annual plasticulture system. HortScience, Alexandria, v.36, n.7, p.1219-1223, 2001.

FILGUEIRA, F.A.R. Rosáceas- morango: um frutinho rasteiro. In: ___ Novo manual de olericultura: agrotecnologia moderna na produção e comercialização de hortaliças. 2.ed. Viçosa: UFV, 2003. p.378-385.

KIRSCHBAUM, D.S. et al. Nitrogen requirements of drip irrigated strawberries grown in subtropical environments. Acta Horticulturae, The Hague, n.708, p.93-96. 2006.

HOCHMUTH, G.J. et al. Nitrogen fertigation requirements of drip-irrigated strawberries. Journal of American Society for Horticultural Science, Mount Vernon, v.121, n.4, p.660$665,2006$.

MACIT, I. et al. Yield, quality and nutritional status of organically and conventionally-grown strawberry cultivars. Asian Journal of Plant Sciences, Islamabad, v.6, n.7, p.11311136, 2007.

MACHADO, A.A.; CONCEIÇÃO, A.R. Sistema de análise estatística para Windows. Winstat. Versão 2.0. Pelotas: UFPel, 2003.

MARTINS, D.S. Produção e qualidade de frutas de diferentes cultivares de morangueiro em sistema de produção de base ecológica. 2010. 81f. Dissertação (Mestrado em Sistema de Produção Agrícola Familiar) Universidade Federal de Pelotas, RS.

MAZOYER, M.; ROUDART, L. Sustainability of agricultures and globalization. In.: CRISTOIU, A. et al. Sustainability of the farming systems: global issues, modelling approaches and policy implications. Seville, Institute for Prospective Technological Studies, 2007. 252p.

MIRANDA, F.R. et al. Uso de efluentes da carcinicultura de águas interiores na irrigação do arroz. Revista Engenharia Sanitária Ambiental, Rio de Janeiro, v.13, n.4, p.380-386, 2008.

OLIVEIRA, R.P. et al. 'Camino Real': nova cultivar de morangueiro recomendada para o rio Grande do Sul. Pelotas: Embrapa Clima Temperado, 2007. (Comunicado Técnico, 161).

OLIVEIRA, R.P. et al. Produção de morangueiro da cv. 'Camino Real' em sistema de túnel. Revista Brasileira de Fruticultura, Jaboticabal, v.30, n.3, p.681-684, 2008.

PREZOTTI, L.C. Nutrição mineral do morangueiro. In: BALBINO, J.M. de S. (Ed.). Tecnologias para produção, colheita e pós-colheita de morangueiro. 2.ed. Vitória: Incaper, 2006. p.37-40. 
SANTOS, B.M. Effects of preplant nitrogen and súlfur fertilizer sources on strawberry. HortTechnology, Alexandria, v.20, p.193-196, 2010.

SHAW, D.V. Strawberry production systems, breeding and cultivars in California. In: SIMPÓSIO NACIONAL DO MORANGO, 2.; ENCONTRO DE PEQUENAS FRUTAS E FRUTAS NATIVAS, 2004, Pelotas, RS. Palestras... Pelotas: Embrapa Clima Temperado, 2004. p.15-20. (Embrapa Clima Temperado. Documentos, 124).

SILVA, F.L.B. et al. Interação entre salinidade e biofertilizante bovino na cultura do feijão-de-corda. Revista Brasileira de Engenharia Agrícola e Ambiental, Campina Grande, v.15, n.4, p.383-389, 2011. Disponível em: <http://www.scielo.br/ s c i e lo.php? s c ript=s c i_pdf \& pid=S 1415 $43662011000400009 \& \operatorname{lng}=p t \& n r m=i s o \& \ln g=p t>$. Acesso em: 01 fev. 2011

SOUZA, E.C.A. Uso agronômico do fosfato natural. 2.ed. rev. São Paulo: Unesp, 1996. 47p.

STRASSBURGER, A.S. Crescimento, partição de massa seca e produtividade do morangueiro em sistema de cultivo orgânico. 2010. 121f. Tese (Doutorado em Sistema de Produção Agrícola Familiar) - Universidade Federal de Pelotas, RS

UENO, B. Manejo integrado de doenças do morango. In: SIMPÓSIO NACIONAL DO MORANGO, 2., 2004, Pelotas-RS. Anais... Pelotas: Embrapa Clima Temperado, 2004. p.69-77. 